\title{
Microstrip-fed Triangular UWB Microstrip Antenna Based on DGS
}

\author{
Abdurrahim Toktas ${ }^{*}{ }^{1}$, Mehmet Yerlikaya ${ }^{1}$, Enes Yiğit ${ }^{1}$
}

Accepted $3^{\text {rd }}$ September 2016

\begin{abstract}
An ultra-wideband (UWB) monopole microstrip antenna is designed in this study. The design consists of a radiating triangular patch antenna (TPA) fed through a $50 \mathrm{Ohm}$ microstrip transmission line (MTL) constructed over a defected ground structure (DGS). The triangular monopole well is matched to MTL with inserting a thin strip line. The performance of the proposed antenna is numerically investigated using method of moments $(\mathrm{MoM})$ and verified through measurements. Based on the measured results, the antenna operates over large frequency range of 2.6-18.2 GHz at $-10 \mathrm{~dB}$. This makes the design suitable for UWB applications. The proposed antenna has better characteristics in terms of radiation pattern, peak gain and total efficiency across the operating ultra-wideband frequency range. Furthermore, the antenna system is suitable for near-millimetre wave applications, since the operating band reaches to $18.2 \mathrm{GHz}$.
\end{abstract}

Keywords: Antennas, patch antennas, triangular antennas, antenna designing, ultra-wideband $(U W B)$ systems, defected ground structure $(D G S)$.

\section{Introduction}

The ultra-wideband (UWB) systems have received considerable attention in recent years due to allowing signal transmission in a large bandwidth with a low energy level. Radar imaging, mobile and satellite communications, multimedia streaming, biomedical imaging are the most important application areas of ultrawideband systems [1-5]. The ultra-wideband systems have been further studied especially since Federal Communications Commission (FCC) approved the unlicensed use of the frequency range of 3.1-10.6 GHz for low power emitting implementations [6].

Patch antennas are widely used in the wireless systems due to various advantages such as low profile, small size, light weight, conformability to mounting host and capability of integration into the arrays. Owing to these advantages, the printed antennas have been integrated to the latest wireless communications of wireless local area network (WLAN), long term evolution (LTE) and worldwide interoperability for microwave access (Wi-MAX) standards, and ultra-wideband systems. Designing an appropriate antenna is the most important part of ultra-wideband applications because it effects the whole system performance.

There are several antenna structures that can be used for ultrawideband systems such as the Vivaldi antenna [7], log periodic antenna [8], spiral antenna [9] and monopole antenna [10-18]. Monopole designs show inherently wideband behaviour as well as omni-directional radiation pattern. Therefore the printed forms of that designs can be successfully exploited for ultra-wideband systems. Over the past years, several monopole antenna structures, such as rectangular [10], circular [11], elliptical [12], conical [13], tapered [14, 15], slot-loaded [16-18] and defected ground [19-22] configurations, have been suggested for ultrawideband applications.

The popularity of defected ground structure (DGS) in antenna study has increased immensely [19-22]. The DGS is basically obtained by properly modifying the ground plane of a patch

\footnotetext{
${ }^{1}$ Department of Electrical and Electronics Engineering

Engineering Faculty, Karamanoglu Mehmetbey University

70100, Karaman/ Turkey

* Corresponding Author: Email: atoktas@kmu.edu.tr

Note: This paper has been presented at the $3^{\text {rd }}$ International Conference

on Advanced Technology \& Sciences (ICAT'16) held in Konya (Turkey), September 01-03, 2016.
}

antenna. Thus compact designs with high characteristics of especially wideband and gain can be achieved.

In this study, an ultra-wideband triangular patch antenna (TPA) that consists of a triangular monopole is designed. The triangular monopole is positioned on a rectangular DGS. The triangular radiating monopole patch is fed through a microstrip transmission line (MTL). The TPA is modelled in HyperLynx 3D EM simulation software based on method of moments (MoM) and fabricated for measurements. The TPA with a small size of $23 \times 31$ $\mathrm{mm} 2$ operates across $2.6 \mathrm{GHz}$ to $18.2 \mathrm{GHz}$ based on measured results.

\section{The Structure of DGS-Based TPA}

The TPA structure is composed of a $14 \times 23 \mathrm{~mm} 2$ triangular monopole patch fed by 50 Ohm MTL and a 17x23 mm2 rectangular DGS. The 3D geometry of the TPA model is depicted in Figure 1 and its dimensions are given in Table I. The radiating plane is placed over a $1.6 \mathrm{~mm}$ height substrate with 4.4 relative di-electric constant on the DGS. Therefore, the TPA has a total dimension of $23 \times 31 \times 1.6 \mathrm{~mm} 3$. In order to improve the impedance matching, a $1 \mathrm{~mm}$ thin strip line is inserted between triangular radiating patch and the MTL.

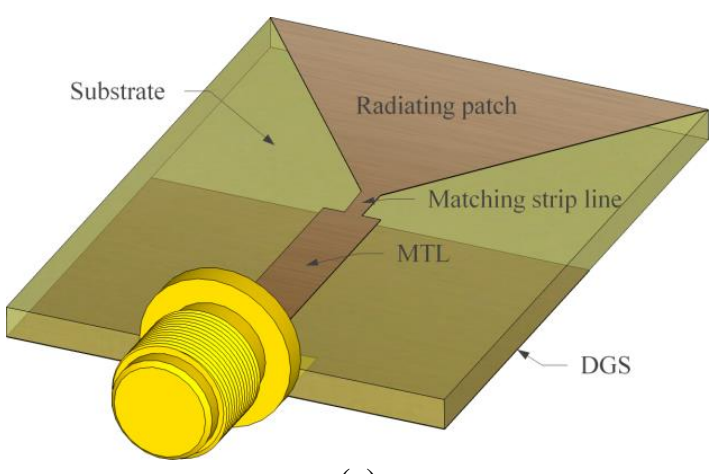

(a) 


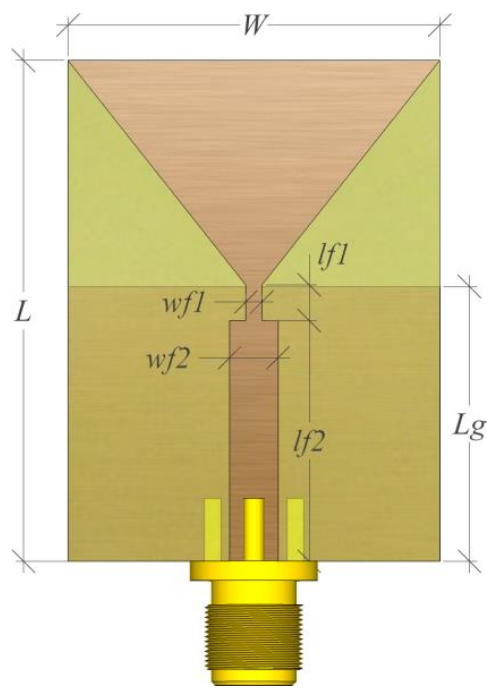

(b)

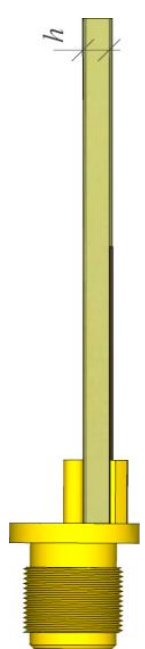

(c)

Figure 1. The 3D geometry of the TPA a) perspective view, b) front view, c) side view

Table 1. Dimensions of the TPA (Unit: mm)

\begin{tabular}{cccccccc}
\hline \hline$h$ & $W$ & $L$ & $L_{g}$ & $w_{f 1}$ & $w_{f 2}$ & $l_{f 1}$ & $l_{f 2}$ \\
\hline 1.6 & 23 & 31 & 17 & 1 & 3 & 2.2 & 14.9 \\
\hline \hline
\end{tabular}

\section{The TPA Design Procedure}

In design process, different patch forms are assayed in order to achieve an ultra-wideband operation. To further understand the evaluation of the proposed antenna system, the designing steps are investigated in four cases: Case I, II, III and IV as illustrated in Figure 2.

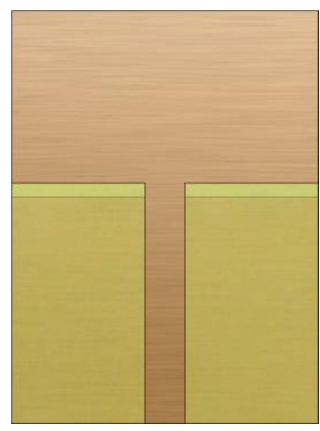

(a)

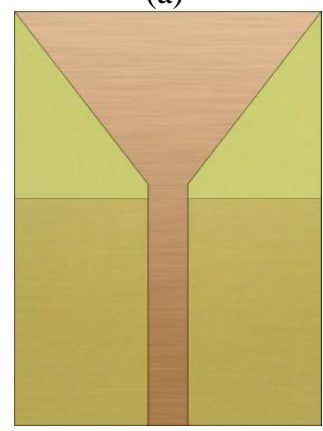

(c)

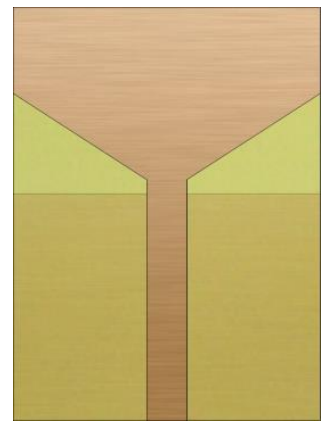

(b)

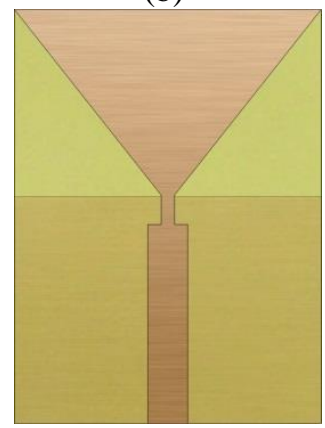

(d)

Figure 2. The antenna designing steps: a) Case I, b) Case II, c) Case III, d) Case IV

The simulated $\mathrm{S}_{11}$ parameters related to the cases are accordingly shown in Fig. 3. In Case I, the design procedure is started with a $14 \times 23 \mathrm{~mm} 2$ rectangular radiating patch fed by $50 \mathrm{Ohm}$ MTL and a DGS. The DGS is obtained by shortening the ground plane size

of $31 \times 23 \mathrm{~mm} 2$ to $17 \times 23 \mathrm{~mm} 2$ so as to obtain an effective radiation. Since the radiation field occurs mainly between the radiating patch and the ground edges facing to each other, modifications on these edges can yield a satisfactory results. Therefore, in Case II, the radiating edges facing to the fixed DGS are triangularly trimmed to increase the impedance bandwidth as can be seen in Figure 3. Once a better results are achieved by this way, the triangular cut's angle with the DGS is increased to further improve the impedance matching as in Case III. Note that the $50 \mathrm{Ohm}$ MTL uniformly continues from the port to the input of the triangular radiating patch. Owing the radiation starting from the end of DGS, a thinner strip is needed to match the input impedance of the triangular radiating patch to the MTL. A strip is hence designed between those in Case IV which is the final form of the designed antenna system.

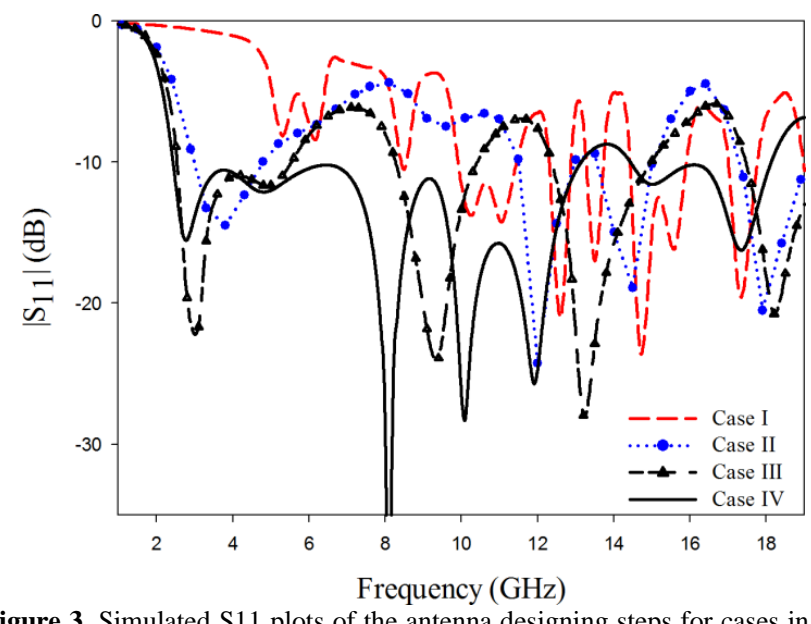

Figure 3. Simulated S11 plots of the antenna designing steps for cases in Figure 2

\section{The Current Mechanism of The TPA}

The simulated surface current distributions of the TPA at the frequency points of $2.7 \mathrm{GHz}, 8.1 \mathrm{GHz}$ and $11.9 \mathrm{GHz}$ are presented in Figure 4. From the figure, the current distributions for these frequencies vary in similar to each other. As mentioned above in Section III that the radiation field comes about the facing edges, it can also be observed from the current distributions, the source current of that radiation is mostly concentrated at those edges. In addition, the majority of the current intensifies at the side edges of the matching strip line since it behaves as a resonator. This means that it does not only match the input impedance but also highly contributes to the radiation.

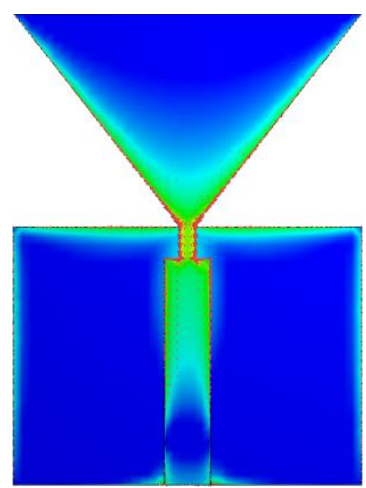

(a) 


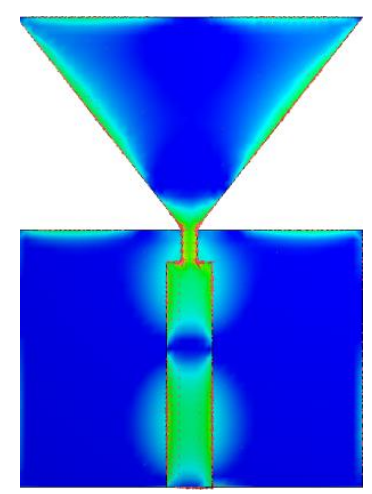

(b)

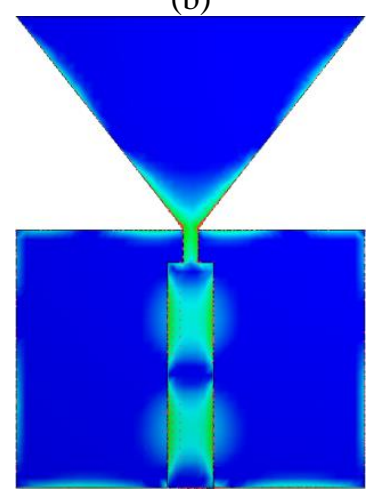

(c)

Figure 4. Surface current distributions of the TPA: a) $2.7 \mathrm{GHz}$, (b) 8.1 $\mathrm{GHz}$, (c) $11.9 \mathrm{GHz}$

\section{Fabricating a Prototype of The TPA}

The prototype of the TPA is shown in Figure 5. The antenna model is etched with the use of a computer numerical control (CNC) machine on a double side 1.6 height FR4 substrate with a relative dielectric constant of 4.4 and a tangent loss of 0.017 .

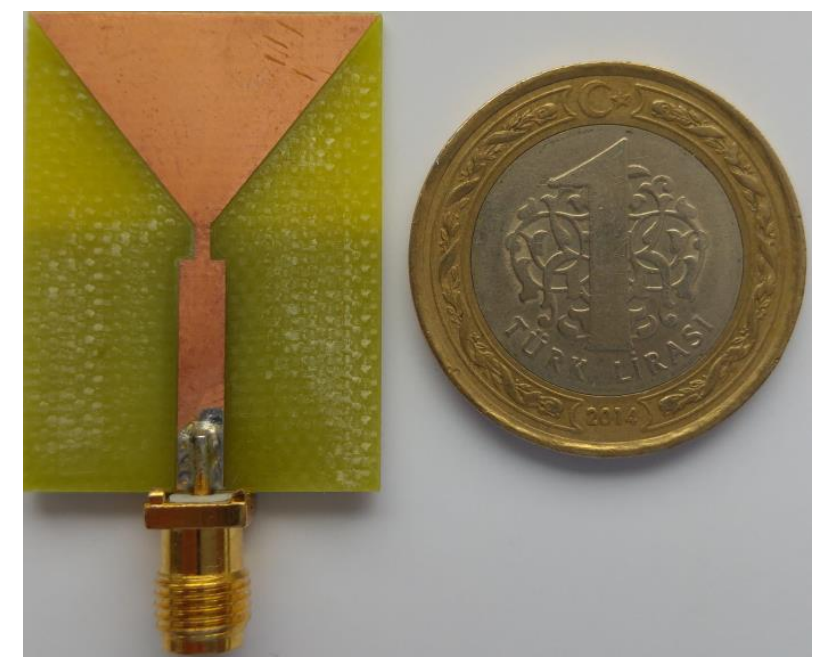

Figure 5. The photograph of the fabricated TPA

The measurements are carried out by the agency of Keysight Technologies N5224A PNA network analyser. The measured $S_{11}$ parameters in comparison with the simulated ones are plotted in Figure 6. Based on the measured results, the TPA operates between $2.6 \mathrm{GHz}$ and $18.2 \mathrm{GHz}$. It should be noticed that discrepancies between the simulated and measured curves might be attributed to the small mismatches of geometry, dielectric, thicknesses, copper cladding and feeding between the simulated models and the prototype.

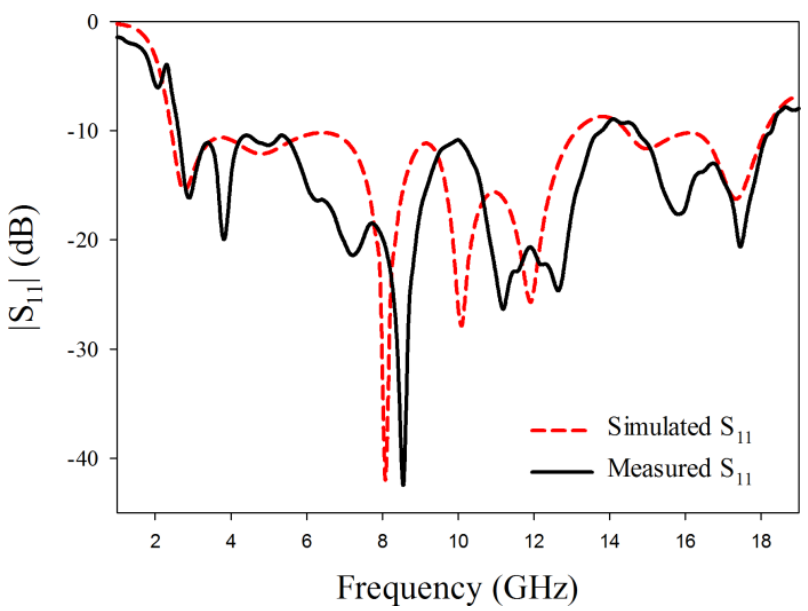

Figure 6. Measured and simulated S11 parameters of the prototyped TPA

\section{Radiation, Gain and Efficiency Characteristics}

Simulated 2D gain radiation patterns of the TPA at the frequency points of $2.7 \mathrm{GHz}, 8.1 \mathrm{GHz}$ and $11.9 \mathrm{GHz}$ are illustrated in Figure 7. The maximum gains are $2.14 \mathrm{~dB}$ (in direction of $180^{\circ}$ on $\mathrm{x}-\mathrm{z}$ plane), $2.2 \mathrm{~dB}$ (in direction of $185^{\circ}$ on $\mathrm{y}$-z plane) at 2.7 $\mathrm{GHz}$; and $2.42 \mathrm{~dB}$ (in direction of $90^{\circ} / 270^{\circ}$ on $\mathrm{x}-\mathrm{z}$ plane), $1.9 \mathrm{~dB}$ (in direction of $320^{\circ}$ on $\mathrm{y}-\mathrm{z}$ plane) at $8.1 \mathrm{GHz}$. Likewise, they are $1.6 \mathrm{~dB}$ (in direction of $145^{\circ} / 215^{\circ}$ on $\mathrm{x}-\mathrm{z}$ plane) and $0.2 \mathrm{~dB}$ (in direction of $45^{\circ} / 315^{\circ}$ on y-z plane) at $11.9 \mathrm{GHz}$.

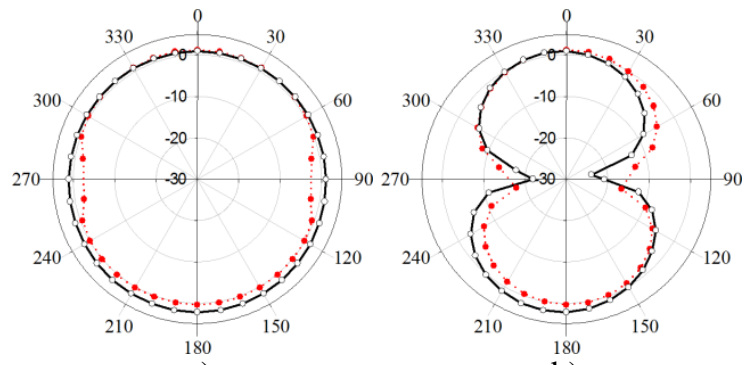

a)

b)

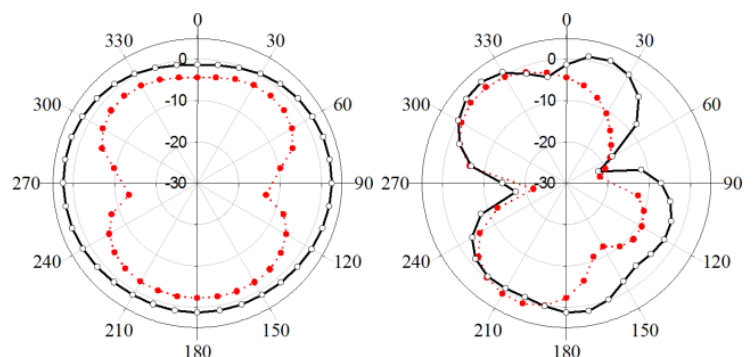

c)

(d)

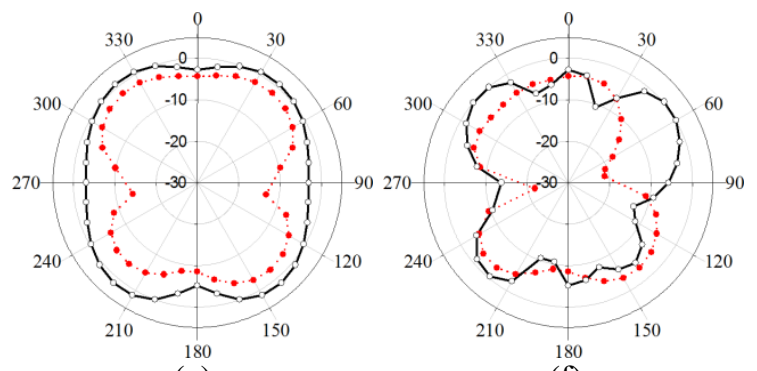

(e)

(f)

Figure 7. Measured and simulated radiation gain patterns of TPA at: a) $2.7 \mathrm{GHz}$ on $\mathrm{x}-\mathrm{z}$ plane, b) $2.7 \mathrm{GHz}$ on $\mathrm{y}-\mathrm{z}$ plane, c) $8.1 \mathrm{GHz}$ on $\mathrm{x}-\mathrm{z}$ plane, d) $8.1 \mathrm{GHz}$ on $\mathrm{y}-\mathrm{z}$ plane, e) $11.9 \mathrm{GHz}$ on $\mathrm{x}-\mathrm{z}$ plane, f) $11.9 \mathrm{GHz}$ on $\mathrm{y}-\mathrm{z}$ plane (solid line measured, dot line is simulated) 
Figure 8 indicates the peak gain together with the total efficiency of the TPA. It is known that total efficiency of an antenna is the product of the efficiencies relevant to radiation, mismatch, conduction and dielectric. From the figure, the peak gain changes between $2.2 \mathrm{dBi}$ and $4.5 \mathrm{dBi}$ levels across the interested frequency band, whereas a minimum gain occurs $2.2 \mathrm{dBi}$ at 2.7 $\mathrm{GHz}$ and maximum gain take places $4.5 \mathrm{dBi}$ at $16 \mathrm{GHz}$. On the other hand, the total efficiency keeps higher than 66\%. The highest and second highest total efficiencies are $94 \%$ and $93 \%$ at $2.7 \mathrm{GHz}$ and $5 \mathrm{GHz}$, respectively.

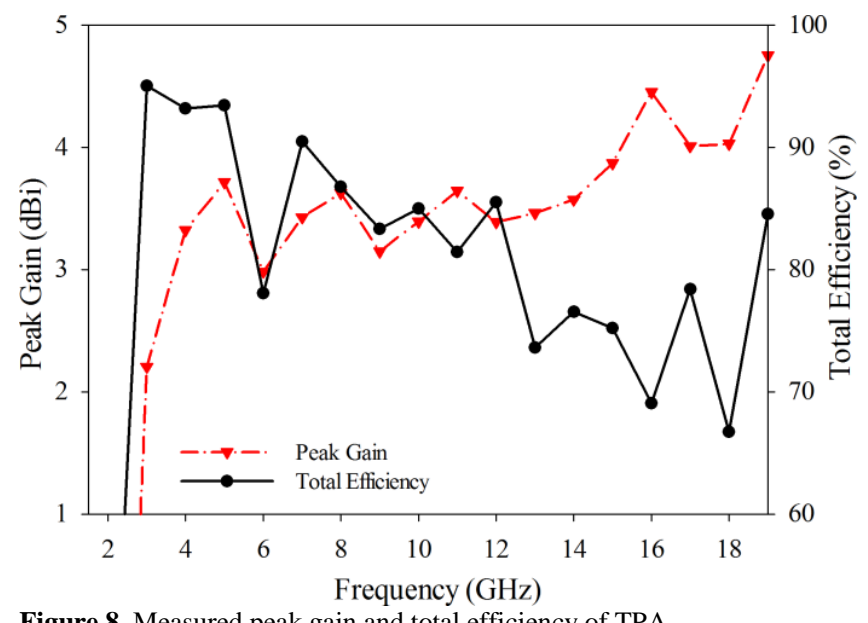

Figure 8. Measured peak gain and total efficiency of TPA

\section{Conclusion}

In this work, we presented a compact ultra-wideband monopole patch antenna design operating over a large frequency range of 2.6-18.2 GHz. The monopole TPA fed via a MTL is built on a half-length DGS. The whole antenna system has a small size of $23 \times 31 \mathrm{~mm} 2$. A thinner strip line is inserted between the triangular monopole and the MTL to improve the impedance matching. The proposed TPA is verified by simulation and validated through measurement. The TPA has superior characteristics of larger bandwidth than the regulated ultra-wideband of $3.1-10.6 \mathrm{GHz}$, near omni-directional pattern, uniform gain and high efficiency. In conclusion, since the TPA operates up to $18.2 \mathrm{GHz}$ it can be also utilized for near-millimeter wave applications.

\section{Acknowledgements}

This work is supported by the Scientific Research Fund Department of Karamanoglu Mehmetbey University, under grant no: $12-\mathrm{M}-15$.

\section{References}

[1] D. W. Winters, J.D. Shea, E. L. Madsen, G. R. Frank, B. D. Van Veen, and S. C. Hagness, "Estimating the breast surface using UWB microwave monostatic backscatter measurements," IEEE Transactions on Biomedical Engineering, vol. 55, pp. 247-256,2008.

[2] S. Nag, M. A. Barnes, T. Payment, and G. W. Holladay, "An ultra-wideband through-wall radar for detecting the motion of people in real time", Proc. SPIE, Radar Sensor Technology and Data Visualization, 2002, vol. 4744.

[3] D. L. Sostanovsky, A. O. Boryssenko, and E. S. Boryssenko, "UWB radar imaging system with twoelement receiving array antenna", Proc. IEEE 5th
International Conference on Antenna Theory and Techniques, 2005, pp. 357-360.

[4] W. Cui, P. Ranta, T. A. Brown, and C. Reed, "Wireless video streaming over UWB", Proc. IEEE International Conference on Ultra-Wideband 2007, pp. 933-936.

[5] D. Valente, E. Cianca, S. Mukherjee, T. Rossi, M. Ruggieri, and R. Prasad, "Comparison of UWB approaches applied to ehf satellite communications", Proc. IEEE Aerospace Conference 2012, pp. 1-6.

[6] Federal Communications Commission, "FCC report and order on ultra wideband technology", Washington DC, 2002.

[7] S. G. Kim and K. Chang, "Ultra wideband exponentiallytapered antipodal vivaldi antennas", Proc. IEEE Antennas and Propagation Society Symposium, 2004, pp. 2273-2276.

[8] S. Y. Chen; P. H. Wang; and P. Hsu, "Uniplanar logperiodic slot antenna fed by a CPW for UWB applications", IEEE Antennas and Wireless Propagation Lett., vol. 5, pp. 256-259, 2006.

[9] B. A. Kramer, M. Lee, C. C. Chen, and J. L. Volakis, "Design and performance of an ultra-wideband ceramicloaded slot spiral", IEEE Transactions on Antennas and Propagation, vol. 53, pp. 2193-2199, July 2005.

[10] Q. Wu, R. Jin, J. Geng, M. Ding, "printed omni-directional UWB monopole antenna with very compact size", IEEE Transactions on Antennas and Propagation, vol. 56, pp. 896-899, 2008.

[11] J. Liang, C. C. Chiau, X. Chen, C. G. Parini, "Study of a printed circular disc monopole antenna for UWB systems", IEEE Transactions on Antennas and Propagation, vol. 53, pp. 3500-3504, July 2005.

[12] K. G. Thomas and N. Lenin, "Ultra-Wideband Printed Monopole Antenna", Microwave and Optical Technology Lett., vol. 49, pp. 1082-1085,2007.

[13] S. Y. Suh, W. Stutzman, and W. Davis, "A new ultrawideband printed monopole antenna: the planar inverted cone antenna (PICA)", IEEE Transactions on Antennas and Propagation, vol. 52, pp. 1361-1364, 2004.

[14] A. A. Eldek, "Numerical analysis of a small ultra wideband microstrip-fed tap monopole antenna", Progress In Electromagnetics Research, vol. 65, pp. 59-69, 2006.

[15] J. Jung, W. Choi, and J. Choi, "A small wideband microstrip-fed monopole antenna for UWB WBAN", IEEE Microwave Lett., vol. 15, pp. 703-705, 2005.

[16] F. Yang, X. Zhang, and Y. Rahmat-Samii, "Wideband Eshaped patch antennas for wireless communications", IEEE Transactions on Antennas and Propagation, vol. 49, pp. 1094-1100, 2001.

[17] S. Weigand, G. H. Huff, K. H. Pan, and J. T. Bernard, “ Analysis and design of broadband single layer U-slot microstrip patch antennas", IEEE Transactions on Antennas and Propagation, vol. 51, pp. 457-468, 2003.

[18] A. M. Abbosh and M. E. Bialkowski, "Design of UWB planar band-notched antenna using parasitic elements", IEEE Transactions on Antennas and Propagation, vol. 57, pp. 796-799, 2009.

[19] C. S. Kim, J. S. Park, D. Ahn, and J. B. Lim, “ A novel 1-D periodic defected ground structure for planar circuits", IEEE Microwave and Wireless Components Lett., vol. 10, pp. 131-133, 2000.

[20] M. A. Antoniades and G. V. Eleftheriades, "A compact multiband monopole antenna with a defected ground plane," IEEE Antennas and Wireless Propagation Lett., vol. 
7, pp. 652-655, 2008.

[21] K. H. Chiang and K. W. Tam "Microstrip monopole antenna with enhanced bandwidth using defected ground structure," IEEE Antennas and Wireless Propagation Lett., vol. 7, pp. 532-535, 2008.
[22] A. Nouri and G. R. Dadashzadeh, "A compact UWB bandnotched printed monopole antenna with defected ground structure," IEEE Antennas and Wireless Propagation Lett., vol. 10, pp. 1178-1181, 2008. 